Journal of Al Azhar University Engineering Sector

Vol. 11, No. 38, January, 2016, 95-113

\title{
MODELING AND DESIGN OF THERMAL POWER PLANTS USING CONCENTRATED SOLAR POWER SYSTEMS
}

\author{
Rezq Mohammed Moustafa, and Ahmed El-biomey Mansour \\ Electrical Engineering Department, Al-Azhar University, Cairo, Egypt
}

\begin{abstract}
This paper introduces the configuration of main portions of concentrated solar thermal power plants (CSTPPs). This configuration play a very important role in the operation of these plants. It also proposes for these plants a new compact mathematical modeling which has an advantage that the expressions of most plant portions are free of any complex or thermal details that describe the conventional model [4] and [5].

Depending on that mathematical modeling of CSTPPs components, a flow chart is designed to determine the power flow of each portion and the net output power of the plant. MATLAB program that has more availability in design equations, inputs and outputs editing will be coded and executed. SAM program will also be used to obtain the same results of the CSTPPs obtained by using MATLAP program. The results of both programs are very close showing that the determination of the power flow of each portion and the net output power of the plant is accurate with high confidence degree.
\end{abstract}

KEY WORDS: Concentrated Solar Power, Parabolic Trough, Fresnel, Parabolic Dish And Heliostat Field Collectors, Heat Transfer Fluid Htf, Thermal Energy Storage Tes, Power Block, Turbine, Alternator, Matlab Program, And Sam Program.

\section{INTRODUCTION}

The Growing demand for solar thermal energy has many causes, including: depletion of the traditional sources of fuel and energy such as oil, higher availability of the sun which is the source of this renewable energy, low cost operation and easy maintenance of these plants. A concentrated solar thermal power plant works nearly in the principle as conventional steam power plant. However, there is an important difference that there is no harm to the environment as in the case of burning coal, oil, natural gas or by splitting uranium to produce steam. The steam is produced only by the energy that comes from the sun [1]. The solar power can be collected by the concentrated solar power systems which collect the solar insolation to concentrated insolation beams on the receiver, and then the beams are used to heat some heat transfer fluid (HTF) which will operate steam turbine in the final.

Let's consider quickly some statistics; in full sun, about 100 watts of solar energy per square foot hits the earth [2]. The great idea is to translate the sun's energy in a form to usable electricity. In most cases, the CSTPPs are used to produce this electricity power, usually generated through steam [3]. Then accurate design is performed to determine the power flow of each portion and the net output power of the plant [18].

All concentrated solar thermal power plants consist of three main parts which are: solar field, energy storage system and finally, the power generation block. In the past, a CSTPPs modeling was very difficult. It depends on complex physical and thermal relationships. It uses programming languages that have old and difficult coding [11]. The modeling of the overall 
solar thermal power plants in good expressive equations requires good known for each part of the plant. Using these equations, it's easy to code new design program by using MATLAB in statements profile. Another program which is called SAM program is used to design the concentrated solar thermal power plants and to insure that the results of the design program are accurate with very high confidence.

\section{CONFIGURATION OF CONCENTRATED SOLAR THERMAL POWER}

\section{PLANTS}

The concentrated solar thermal Power Plants have three main parts, as following;

A.

SOLAR FIELD

The solar field is composed of rows of collectors as shown in (figure 3). An array of tracking collectors can be arranged in distributed system so that the working fluid of each collector is piped until attaining a central power conversion station [6]. The collectors follow the sun to catch energy as much as possible. In this stage; the solar radiations are collected by concentrated solar collectors, then these collectors reflect the solar radiations to the receiver tube, so the internal liquid (or any working heat transfer fluid HTF) in the receiver tube will transfer the heat to the thermal storages [7]. There are mainly four types of solar collectors: parabolic trough collector, linear fresnel reflector, Parabolic dish and heliostat collector (central receiver power tower).

B. SOLAR THERMAL ENERGY STORAGE (STES)

Generally, energy storage (ES) is critically important to the success of any intermittent energy source to meet the continuous demand. For solar energy applications, the storage is severe until when it is only required to be available in the night [8].

The main idea of thermal energy storage is charging a material with the heat by increase its temperature and discharging of the heat from it by decrease its temperature [9]. Thermal energy quantity in a material varies with varying of its temperature [10]. The energy required $E$ to heat a volume $V$ of a substance from a temperature $T_{1}$ to a temperature $T_{2}$ is given by [8]: $E=m C\left(T_{2}-T_{1}\right)=\rho V C\left(T_{2}-T_{1}\right)$

Where $E$ in $\mathrm{kcal}, C$ is the specific heat of the substance in $\mathrm{kcal} / \mathrm{kg}{ }^{\circ} \mathrm{C}, m$ is the substance mass in $\mathrm{kg}$, and $\rho$ is its density in $\mathrm{kg} / \mathrm{m}^{3}$. The value of $C$ may vary from about $1 \mathrm{kcal} / \mathrm{kg}{ }^{\circ} \mathrm{C}$ for water to $0.0001 \mathrm{kcal} / \mathrm{kg}{ }^{\circ} \mathrm{C}$ for some iron materials.

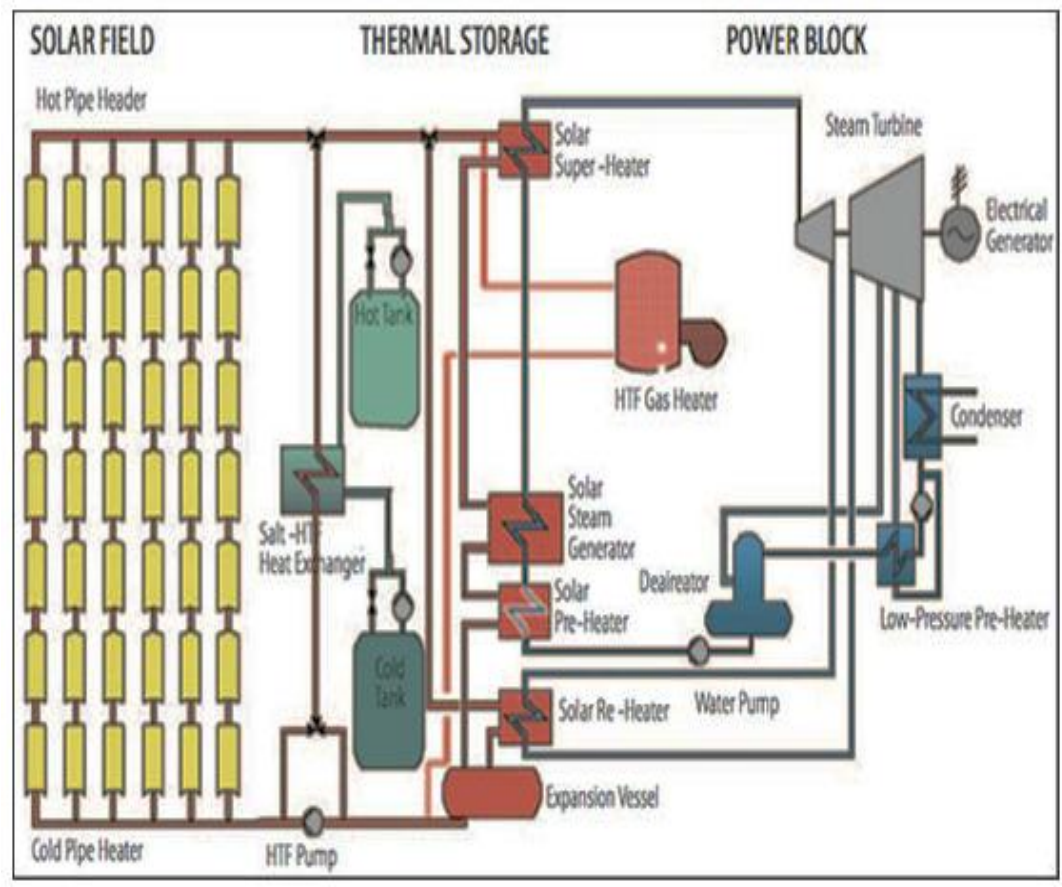

(Fig. 1) Layout of a concentrated solar thermal power plant. 


\section{POWER GENERATION SYSTEM ( POWER BLOCK )}

The power block is the "heart" of the CSTPPs. The thermal energy delivered either from storage or from the solar field is transferred into electrical energy. The power block commonly used in concentrating solar thermal power plants is a Regenerative Rankine Cycle, which is describing the commonly process of steam-operated turbine in thermal power plants to generate electricity power. The working principle of this cycle is: the working fluid is pumped to a boiler where it is evaporated, passed through an expansion device (turbine or other expander). In the final, passed through a condenser heat exchanger where it is recondensed (regenerate) [9].

The heat transfer fluid (HTF) passes through three heat exchangers (simplified model): superheater, boiler and preheater. In the preheater, which is normally a shell and tube type heat exchanger, the compressed water coming from closed feedwater heater is heated up until saturated liquid condition is reached. Then, the saturated liquid flows through the boiler where a change of phase from liquid to vapor occurs [12] and [21]. The boiler (steam generator) is a shell-and-tube heat exchanger with the HTF entering the tube side and liquid feedwater flowing through the shell side. After the boiler, the saturated vapor goes to the superheater where additional energy is added to the steam, bringing it to a superheated vapor condition [10]. This heat exchanger is a shell-and-tube type as well. The superheated steam is expanded through the high pressure turbine as shown in (figure 2).

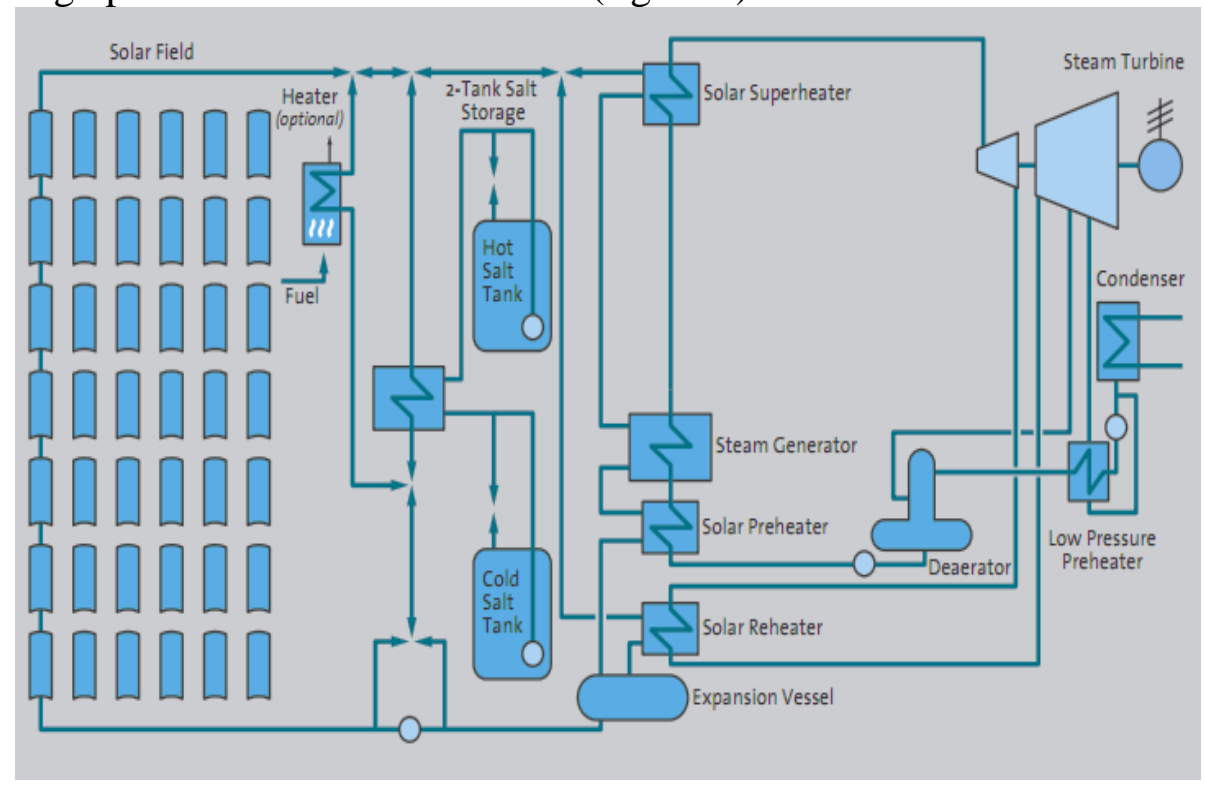

(Fig. 2) Schematic diagram of CSP plant with the power block components.

\section{THE CONVENTIONAL MODEL}

The daily average radiation on a horizontal surface $H_{O}$ is modeled as a function of the solar constant $E_{s c}$, as [4]:

$H_{O}=(24 / \pi) h_{s s} R E_{s c} \sin h_{o}$

where $H_{O}$ and $E_{s c}$ are in $\mathrm{KW} / \mathrm{m}^{2}, R$ is the monthly average sun earth correction factor, which is founded in long tables, $h_{o}$ is the daily average solar elevation outside of the atmosphere in meters, and $h_{s s}$ is the sunset hour angle in radians defined during polar days and nights by the following equation [5]:

$h_{s s}= \begin{cases}0 & \text { if }-\tan L \tan \delta s>1 \\ \pi & \text { if }-\tan L \tan \delta s<-1\end{cases}$

(3) where $L$ is

the solar altitude in meters and $\delta s$ is the monthly average declination angle in radians. The daily average solar elevation outside of the atmosphere is modeled as: 
$h_{o}=q A\left(h_{s s}\right) / h_{s s}$

where:

$q=\cos L \cos \delta s$

$A\left(h_{s s}\right)=\sin h_{s s}-h_{s s} \cos h_{s s}$

The solar geometry need to be determined for only an average day of each month which is shown in standard tables found in [4].

The collector shown in (figure 3) was modeled starting by an energy balance of HTF (the heat transfer fluid), which leads to the following partial differential equation which interrelates the change of $H T F$ energy $\triangle Q_{H T F}$ with the position. The change of $H T F$ energy is considered as a function of the distance along the collector $Z$ and the time $t$.

$\frac{\partial}{\partial t}\left(\Delta Q_{H T F}(z, t)\right)=Q_{H T F}^{\prime}(z, t)-Q_{H T F}^{\prime}(z+\Delta z, t)+q_{\text {gained }}(z, t) \Delta z$

In previous equation, $Q_{H T F}^{\prime}$ is the differential of $H T F$ energy change and $q_{\text {gained }}$ is the heat transfer per unit length between the absorber and the $H T F$.

According to thermodynamics science, it follows that:

$\Delta Q_{H T F}(z, t)=\rho_{H T F} C_{H T F} A_{A B S i} \Delta z T_{H T F}(z, t)$

with $\rho_{H T F}, C_{H T F}, T_{H T F}$ as density in $\mathrm{kg} / \mathrm{m}^{3}$, specific heat in $\mathrm{kcal} / \mathrm{kg}{ }^{\circ} \mathrm{C}$ and temperature of the $H T F$ in ${ }^{\circ} \mathrm{C}$, and $A_{A B S i}$ is The cross sectional area of the inside tube of the absorber in $\mathrm{m}^{2}$. All the collector dimensions are given in tables in metric units profile.

$Q_{H T F}^{\prime}(z, t)=d Q_{H T F}(z, t) / d t$

$$
=\rho_{H T F} C_{H T F}\left(V_{H T F}(t) / n_{\text {collectors }}\right) T_{H T F}(z, t)
$$

where $V_{H T F}(t)$ is the overall $H T F$ volume flow rate in $\mathrm{m}^{3} / \mathrm{s}$ and depends only on the time $t$ since the fluid is considered to be incompressible. $n_{\text {collectors }}$ is the number of collectors [4]. Substituting equations (8) and (9) into equation (7), it follows that:

$$
\begin{aligned}
\rho_{H T F} C_{H T F} A_{A B S i} \Delta z \frac{\partial}{\partial t}\left(T_{H T F}(z, t)\right) & =\rho_{H T F} C_{H T F}\left(V_{H T F}(t) / n_{\text {collectors }}\right) T_{H T F}(z, t) \\
& -\rho_{H T F} C_{H T F}\left(V_{H T F}(t) / n_{\text {collectors }}\right) T_{H T F}(z+\Delta z, t) \\
& +q_{\text {gained }}(z, t) \Delta z
\end{aligned}
$$

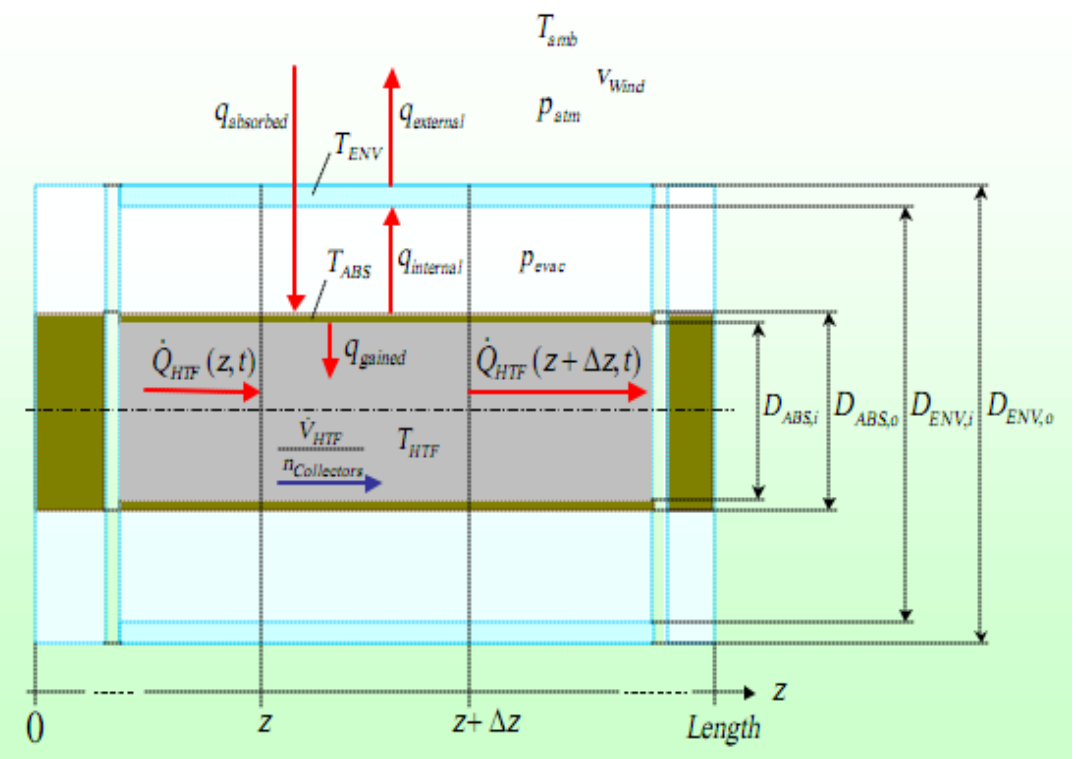

(Fig. 3) Schema of the collector modeling. 
The simplified conventional model shown in (figure 4) consists of four elements: a solar collector, an expansion vessel (the thermal storage tank), a heat exchanger and a HTF pump. These elements are described by the following four nonlinear differential equations. The energy balance on the collector leads to the following differential equation for the $H T F$ temperature $T_{\text {out }}(t)$ at collector outlet [5].

$\begin{aligned} d T_{\text {out }}(t) / d t= & -\left(V_{H T F}(t) / V_{\text {col }}\right) T_{\text {out }}(t)+\left(V_{H T F}(t) / V_{\text {col }}\right) T_{\text {in }}(t) \\ & +\left(L_{\text {col }} / \rho_{\text {HTF }} C_{H T F} V_{\text {col }}\right)\left(q_{\text {absorbed }}(t)-q_{\text {ambient }}(t)\right)\end{aligned}$

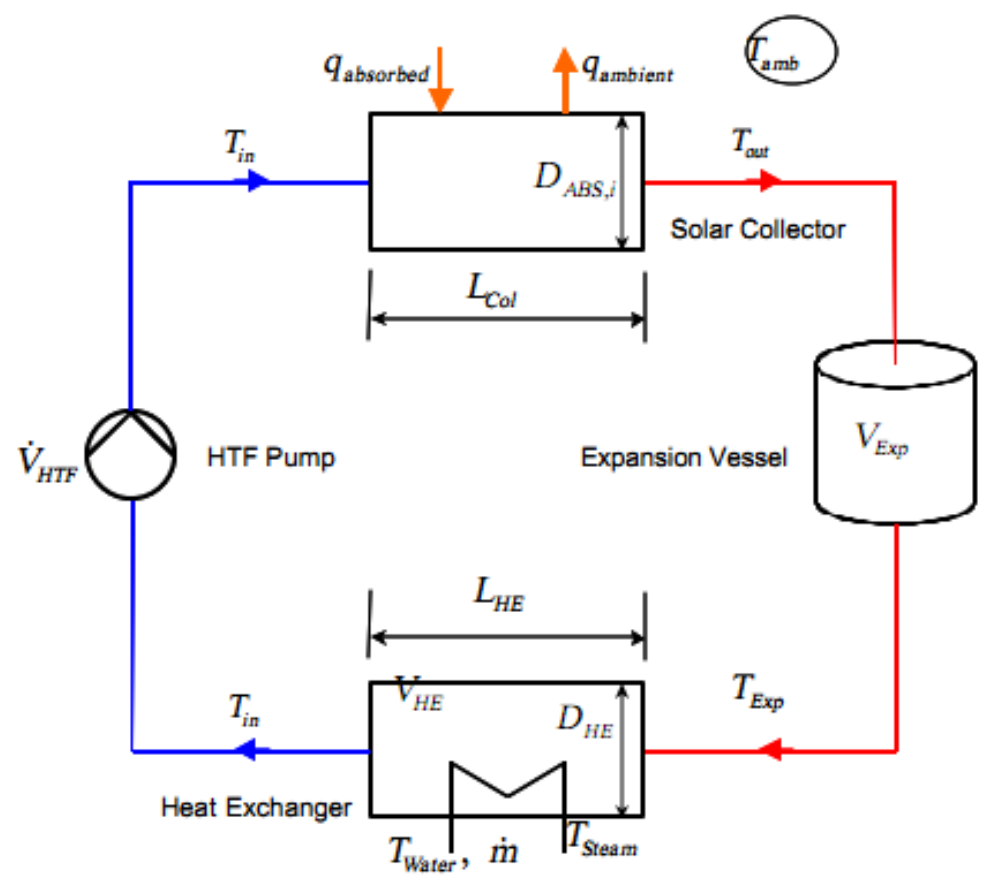

(Fig. 4) the Structure of the Simplified Conventional Model.

where $T_{\text {in }}(t)$ is the $H T F$ temperature at collector inlet in ${ }^{\circ} \mathrm{C}$ and $V_{c o l}$ is the overall volume of the collectors in $\mathrm{m}^{3}$, given by:

$V_{c o l}=\frac{\pi}{4} D_{A B S, I}^{2} L_{c o l}$

with $D_{A B S, I}$ is the collector diameter and $L_{c o l}$ is the length of the collectors in m, given by:

$L_{\text {col }}=$ Length.$n_{\text {collectors }}$

$q_{\text {ambient }}(t)$ is the heat transferred to the environment and $q_{\text {absorbed }}(t)$ is the heat transferred from the sun to the collectors.

The expansion vessel temperature $T_{E x p}(t)$ is determined through

$d T_{E x p}(t) / d t=-\left(V_{H T F}(t) / V_{E x p}\right) T_{E x p}(t)+\left(V_{H T F}(t) / V_{E x p}\right) T_{\text {out }}(t)$

where $V_{E x p}$ is the overall volume of the expansion vessel in $\mathrm{m}^{3}$ [5].

The closed loop of an energy balance for the heat exchanger that leads to

$d T_{\text {in }}(t) / d t=-\left(a_{A}+a_{B}\right)\left(V_{H T F}(t) / V_{H E}\right) T_{i n}(t)+\left(a_{A}+a_{B}\right)\left(V_{H T F}(t) / V_{H E}\right) T_{E X P}(t)$

$$
-\left(L_{H E} / \rho_{H T F} C_{H T F} V_{H E}\right) q_{\text {transferred }}(t)
$$

where $a_{A}$ and $a_{B}$ are the flow fractions, $V_{H E}$ is the overall volume of heat exchanger in $\mathrm{m}^{3}$, $L_{H E}$ is the heat exchanger length in $\mathrm{m}$ and $q_{\text {transferred }}(t)$ is The transferred heat to turbine.

The Steam temperature $T_{\text {steam }}(t)$ is determined from a heat exchanger effectiveness equation:

$\varepsilon_{H E}(t)=\left(T_{\text {steam }}(t)-T_{\text {water }}(t)\right) /\left(T_{E X P}(t)-T_{\text {water }}(t)\right)$

where $\varepsilon_{H E}(t)$ is the heat exchanger effectiveness and $T_{\text {water }}(t)$ is the input water temperature, which will be converted to the steam [5]. 
From the previous model equations, it's clear that these equations are somewhat difficult to be used because they include nonlinear equations. Also, the determination of energy needs to somewhat complex details of thermal and radiations relationships.

\section{NEW COMPACT MODELING OF CONCENTRATED SOLAR THERMAL POWER PLANTS}

Depending on the good study of the main components of the CSTPPs, the modeling of these components will represent the actual system tacking the overall operating conditions into the consideration.

A model of the plant controller monitors the power of each component and determines when the various subsystems of the plant should be operated. The different modeling equations are set to compute the power on a 24-hour basis [14]. One of the main objectives of the modeling is the initiation of the namelist variables and design determination.

A. MODEL OF SOLAR THERMAL COLLECTOR FIELD

The collector field directs the solar radiation incident on the collector onto the receiver. The collector field operates whenever the solar elevation angle, the ambient wind speed and temperature are within specified limits and if there is solar insolation [15]. The power to the receiver $\operatorname{PTR}(K)$ is modeled as:

$\operatorname{PTR}(K)=F * \operatorname{DNI}(K) * F S * 10^{-3}$

where $F$ is the collector field efficiency, $D N I(K)$ is the incident solar radiation at time $K$ in $\mathrm{kW} / \mathrm{m}^{2}, F S$ is the reflective area of collector field in $\mathrm{m}^{2}, P T R(K)$ in $\mathrm{MW}_{\mathrm{t}}$, and $K$ is the current time step, the time majority in hour step.

\section{B. RECEIVER MODEL}

The receiver model must determine receiver operation based on the current power available from the collector field and the previous receiver status in addition to shutdown, startup and rated operation modes. Also, a derated operation mode is included. A limited time holding mode is available for a receiver with doors, permitting instantaneous restart after a period of low insolation [5]. The first section of the receiver model determines if the power to the receiver is within its operational range. If the power to the receiver is greater than the receiver thermal rating, the input is decreased to the thermal rating, simulating collector (or heliostat) defocusing. If the power is less than the minimum, the power input is set to zero and the receiver shuts down (or remains shutdown) or the receiver goes on hold if it has doors. (Figure 5) shows a flowchart representation of this decision-making process for the receiver [12] and [19].

The mode of receiver operation in the previous time step is examined in the next modes. Based on the receiver status and the thermal power available to the receiver (which was just determined), a decision is made for the receiver to remain in its current operational mode or to transit to a new mode. If the receiver is operating, the reflected and thermal power losses are determined. The result is the power transmitted to the working fluid "PTWF" [13]. The Receiver Operation modes are as following:

\section{STEADY-STATE RATED OPERATION}

The receiver remains in rated operation or transits to rated operation when net positive power can be collected. The power to the receiver from the collector field is represented by $\operatorname{PTR}(K)$. The power which can be transferred to the working fluid is:

$P T W F=E P S * P T R(K)-X L R(W S(K))$

where $P T W F$ is thermal power delivered to the working fluid in $\mathrm{MW}_{\mathrm{t}}, E P S$ is receiver absorptivity, $\operatorname{PTR}(K)$ is thermal power delivered by the collector field to the receiver in $\mathrm{MW}_{\mathrm{t}}$, and $X L R(W S(K))$ is receiver thermal loss due to convection and radiation as a function of wind speed in $\mathrm{MW}_{\mathrm{t}}[8]$. 


\section{STEADY-STATE DERATED OPERATION}

The receiver enters a derated operational mode when the power which collected $P T W F$ is less than thermal power equivalent of parasitic power TPEP, but still greater than the minimum power limit of the receiver $R M F * R S$. This is expressed as:

$T P E P>P T W F>R M F * R S$

where $R M F$ is receiver minimum flow fraction and $R S$ is receiver thermal rating, where $R S$ and TPEP are in $\mathrm{MW}_{\mathrm{t}}[9]$.

Derated operation is permitted for three consecutive time steps. After this time, if a receiver without doors shuts down, or a receiver with doors goes into the hold mode [18].

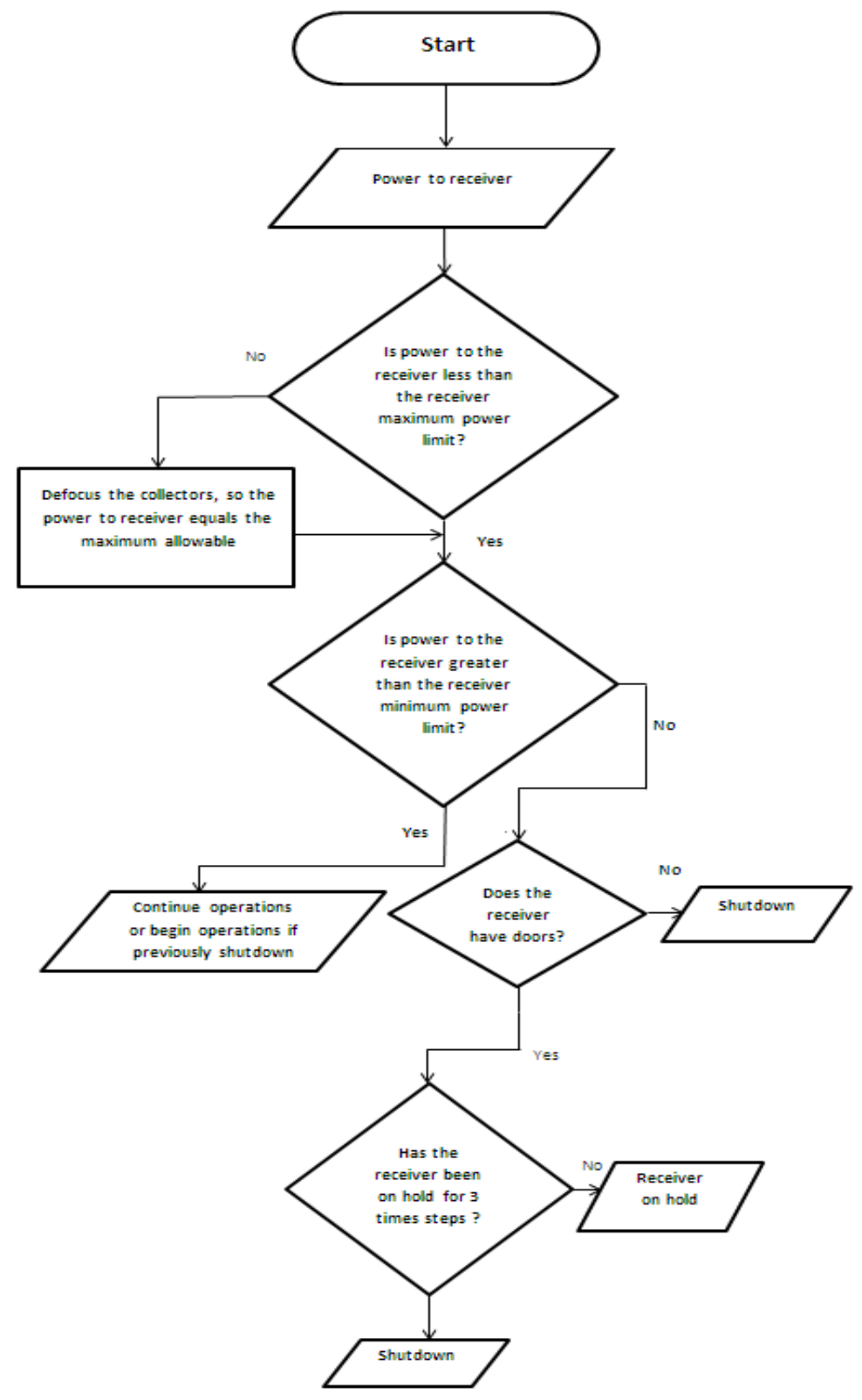

Figure 5. Flowchart of decisions for the receiver operation modes.

C.

PIPING SYSTEM (PIPES) MODEL

The pipe model determines the thermal losses of piping system as a function of dry ambient temperature $D B T$ [13]. The power loss in the piping system is determined as:

$P W F=P T W F-X L P(D B T)$ 
where $X L P(D B T)$ is the power loss in the piping, expressed as a function of the ambient temperature in $\mathrm{MW}_{\mathrm{t}}, P T W F$ is decreased by the piping loss, and $P W F$ is resulting power in the working fluid in $\mathrm{MW}_{\mathrm{t}}$.

\section{THERMAL STORAGE MODEL}

All power from the receiver is sent to thermal storage. Power used to operate the turbine for electrical power generation is extracted from thermal storage. Thus, the storage model responds to the demands placed on it. The modeling is a power flow model [17]. However, thermal storage must be energy based. Power multiplied by the time step gives the energy added to or extracted from thermal storage. Thermal storage is limited by the thermal rating of its charging and extraction heat exchangers, and by its state of charge [18]. The thermal storage operation modes are as following:

\section{NORMAL OPERATION MODE}

Basic equations used in calculating the energy exchanges in thermal storage are the equation for normal operation, a transient charging startup condition and a transient extraction startup condition. The equation for normal operation is as following:

$E N E W=E S+[(P T S-T P L D C)-(T P L F T+T P L B T C)-(P F S+T P L D D)] * D E L T$

where $E S$ is previous amount of energy in storage in $\mathrm{MW}_{\mathrm{t}} \mathrm{hr}, E N E W$ is updated amount of energy in storage in $\mathrm{MW}_{\mathrm{t}} \mathrm{hr}, P T S$ is thermal power delivered to storage by the receiver via the piping system in $\mathrm{MW}_{\mathrm{t}}, T P L D C$ is thermal power lost to the environment in the charging heat exchangers and charging piping in $\mathrm{MW}_{\mathrm{t}}, T P L F T$ is the thermal power lost by the storage tank to the environment in $\mathrm{MW}_{\mathrm{t}}, T P L B T C$ is the thermal power lost through the exchange of heat across the thermocline between the hot and cold regions in $\mathrm{MW}_{\mathrm{t}}, P F S$ is the thermal power delivered to the turbine or process in $\mathrm{MW}_{\mathrm{t}}, T P L D D$ is the thermal power lost to the environment by the extraction heat exchangers and piping in $\mathrm{MW}_{\mathrm{t}}$, and DELT is the time interval in hours. (Figure 6) associates these variables with particular components of thermal storage.

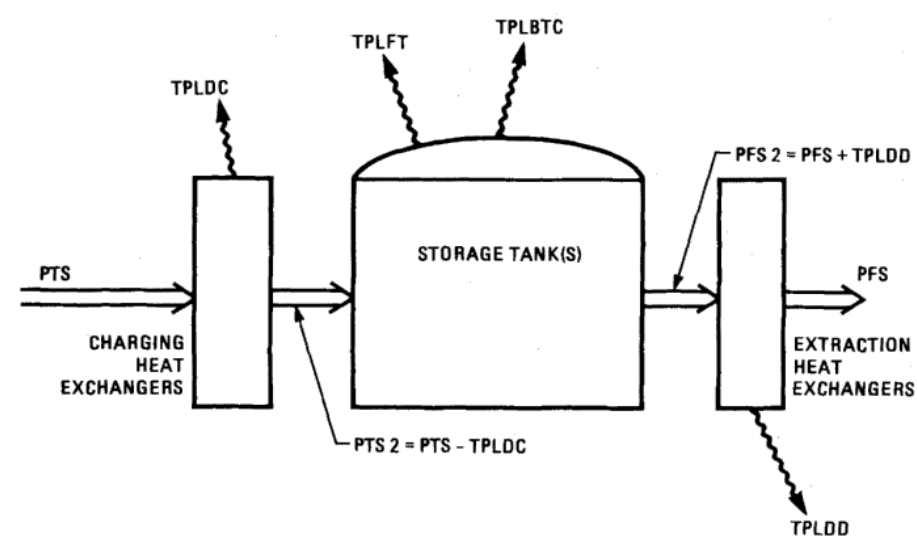

(Fig. 6. Thermal storage variables definition.

\section{TRANSIENT OPERATION}

Since heat exchangers can't be brought from standby to full power operation instantaneously, the storage subroutine provides the user with two tools for modeling the lag associated with bringing of the storage system to rated operating conditions. These lags are: a time lag and an energy lag.

Since some energy must be expended during startup, a startup power must be defined. The maximum startup power levels for the charging and extraction loops are specified by the variables $P W A R M C$ and $P W A R M D$ respectively. The power flow during startup is limited to these values plus the appropriate thermal loss [14]. That is, the charging power limit PTSMAX and the maximum rate of energy extraction from the storage tank during transition PFS2 are: 
$P T S M A X_{(\text {Transient })}=P W A R M C+T P L D C$

$P F S 2=P W A R M D+T P L D D$

The variable $P F S 2$ is the thermal power extracted from the storage tank in $\mathrm{MW}_{\mathrm{t}}$. No thermal energy is delivered to the turbine during extraction startup and no thermal energy is delivered to the thermal storage tank during charging startup. The storage subroutine will remain in the transition mode for charging or extraction until the time and energy delay requirements are met.

\section{E. TURBINE MODEL}

At rated operation and when thermal storage is able to supply sufficient power for rated turbine operation, the thermal to electric conversion efficiency is used to compute the gross electrical output from the turbine. The function EPSS provides the conversion efficiency as a function of ambient wet temperature and steam mass flow rate [20].

$P F T=\operatorname{EPSS}(W B T(K), F M F) * T P F S L$

where $P F T$ is gross electrical power from the turbine in $\mathrm{MW}_{\mathrm{e}}, E P S S$ is turbine thermal to electric conversion efficiency, TPFSL is thermal power required by the turbine for rated operation in $\mathrm{MW}_{\mathrm{t}}, W B T(K)$ is ambient wet temperature in ${ }^{\circ} \mathrm{F}$, and $F M F$ is mass flow fraction. When full power is supplied from thermal storage, the mass flow fraction is unity [9].

$P F T=\operatorname{EPSS}(W B T(K), 1.0) * T P F S L$

\section{F. TOTAL PLANT PARASITICS MODEL}

The total parasitic energy requirement for the plant is calculated on a 24-hour basis as the sum of all operational and nonoperational parasitic energies. The parasitic load is subtracted from the gross electrical plant output to obtain the net electricity produced by the plant [15].

$$
\begin{aligned}
T P P S= & (\text { SPPAR }+ \text { TPPAR }+ \text { BOPPAR })+(P M P A R+S D P A R) \\
= & {\left[(P P M F *(\text { GPOWER }))+\left(P P M F_{T} *(\text { GPOWER })\right)+\left(P P M F_{B} *(G P O W E R)\right)\right] } \\
& +\left[\left(P P M F_{P M} *(G P O W E R)\right)+\left(P P M F_{S D} *(G P O W E R)\right)\right]
\end{aligned}
$$

where TPPS is the total plant parasitics in $\mathrm{MW}_{\mathrm{e}}, S P P A R$ is solar plant parasitics in $\mathrm{MW}_{\mathrm{e}}$, $T P P A R$ is The turbine plant parasitics in $\mathrm{MW}_{\mathrm{e}}, B O P P A R$ is the balance of plant parasitics account for all plant operational parasitics that are not included in either TPPAR or SPPAR in $\mathrm{MW}_{\mathrm{e}}, P M P A R$ is representing the parasitic power at night time and weather outage in $\mathrm{MW}_{\mathrm{e}}$, $S D P A R$ is shutdown parasitics in $\mathrm{MW}_{\mathrm{e}}, P P M F$ is maximum fraction for solar plant parasitics, GPOWER is gross power rating of the plant in $\mathrm{MW}_{\mathrm{e}}, P P M F_{T}$ is maximum fraction for the turbine plant parasitics, $P P M F_{B}$ is maximum fraction for the plant parasitics balance, $P P M F_{P M}$ is maximum fraction for the nonoperational parasitics, $P P M F_{S D}$ is maximum fraction for the shutdown parasitics.

\section{DESGIN DETERMINATION OF THE CONCENTRATED SOLAR THERMAL POWER PLANTS USING MATLAB CODING}

The design determination is coded using MATLAB program in statements profile. This program will determine the operation parameters, generated power, its energy in each part till net power, and other outputs depending on the given inputs of this program.

There are inputs which are required to run the program which will determine the concentrated solar thermal plant. These inputs describe physical and operational details about the plant and provide other information such as the location insolation. The weather case input describes the incident insolation power which will delivery from the sun to the collector for a particular site over one year beginning on 1 January and continuing through 31 December [9]. Program statements will determine the plant output. By these statements, we can modify the inputs to new values in any time to determine the new outputs [16]. The basic program flow chart is shown in (figure 7). For each time step, the collector field model concentrates the incident solar radiation and directs it onto the receiver. By logic, the receiver model decides whether the energy collection portion of the plant will operate based on the level of power delivered by the collector field. All power from the receiver is delivered to thermal storage, provided 
that thermal storage can accept it (i.e. storage is not full). The electricity production portion of the plant can be operated nearly independently from the energy collection portion.

\section{$>\quad$ PROGRAM INPUTS}

These inputs are used to determine and modify the outputs values specified in the program subroutines. These inputs will be described as following.

1. Daily Incident solar radiation data overall the year in monthly profile, $\mathrm{kW} / \mathrm{m}^{2}$.

2. Collector field reflective area, $\mathrm{m}^{2}$.

3. Collector field efficiency, $\%$.

4. Daily receiver thermal loss data overall the year in monthly profile, $\mathrm{MW}_{\mathrm{t}}$.

5. Receiver absorptivity, \%.

6. Daily pipe thermal loss data overall the year in monthly profile, $\mathrm{MW}_{\mathrm{t}}$.

7. Thermal power lost to the environment in the charging heat exchangers and charging piping, $\mathrm{MW}_{\mathrm{t}}$.

8. The thermal power lost by the storage tank to the environment, $\mathrm{MW}_{\mathrm{t}}$.

9. The thermal power lost through the exchange of heat between the hot and cold regions, $\mathrm{MW}_{\mathrm{t}}$.

10. The thermal power lost to the environment by the extraction heat exchangers and piping, $\mathrm{MW}_{\mathrm{t}}$.

11. The turbine efficiency, $\%$.

12. Storage size factor for the energy, $\mathrm{m}^{3} / \mathrm{MW}_{\mathrm{t}} \cdot \mathrm{hr}$.

13. Storage safety factor, $\%$.

14. Electric power conversion efficiency, $\%$.

15. Station land area factor.

$>$ PROGRAM OUTPUTS

These outputs will be given out by the program statements and using inputs values. These outputs are very important in the plant design determination, also some plots will be created. These outputs will be described as following.

1. Daily (24 hour) incident solar radiation over all year in monthly profile, $\mathrm{kW} / \mathrm{m}^{2}$.

2. Daily power incident on receiver over all year in monthly profile, $\mathbf{M W}_{\mathrm{t}}$.

3. Maximum \& minimum incident power on receiver over all year.

4. Daily (24 hour) incident power on receiver in monthly profile.

5. Daily average incident energy on receiver over all year in monthly profile, $\mathrm{MW}_{\mathrm{t}} \cdot \mathrm{hr}$.

6. Daily average incident energy on receiver over all year, $\mathrm{MW}_{\mathrm{t}} \mathrm{hr}$.

7. Daily thermal power delivered to the working fluid overall year in monthly profile, $\mathrm{MW}_{\mathrm{t}}$.

8. Daily net thermal power in the working fluid overall year in monthly profile, $\mathrm{MW}_{\mathrm{t}}$.

9. Maximum daily thermal power (average) in the working fluid overall year, $\mathbf{M W}_{\mathrm{t}}$.

10. The thermal power delivered to the turbine, $\mathrm{MW}_{\mathrm{t}}$. Where the turbine will operate at all the day, and the sunshine is found nearly for $1 / 3$ day ( 8 hour).

11. Daily energy storage, $\mathrm{MW}_{\mathrm{t}} \cdot \mathrm{hr}$.

12. Storage tank volume, $\mathrm{m}^{3}$.

13. Turbine rated output power, $\mathrm{MW}_{\mathrm{t}}$.

14. Maximum net electric power, $\mathrm{MW}_{\mathrm{e}}$.

15. Net annual energy, $\mathrm{MW}_{\mathrm{e}} \cdot \mathrm{hr}$

16. Station land area, $\mathrm{m}^{2}$.

6. SIMULATION PROGRAM OF THE CONCENTRATED SOLAR THERMAL POWER PLANTS USING THE SOLAR ADVISOR MODEL (SAM) SOFTWARE

SAM, originally called the "Solar Advisor Model" was developed by the National Renewable Energy Laboratory in collaboration with Sandia National Laboratories in 2005, and at first used internally by the U.S. Department of Energy. 
SAM's performance model makes hour-by-hour calculations of a power system's electric output, generating a set of 8,760 hourly values that represent the system's electricity production over a single year. You can explore the system's performance characteristics in detail by viewing tables and graphs of the hourly and monthly performance data, or use performance metrics such as the system's total annual output and capacity factor for more general performance evaluations.

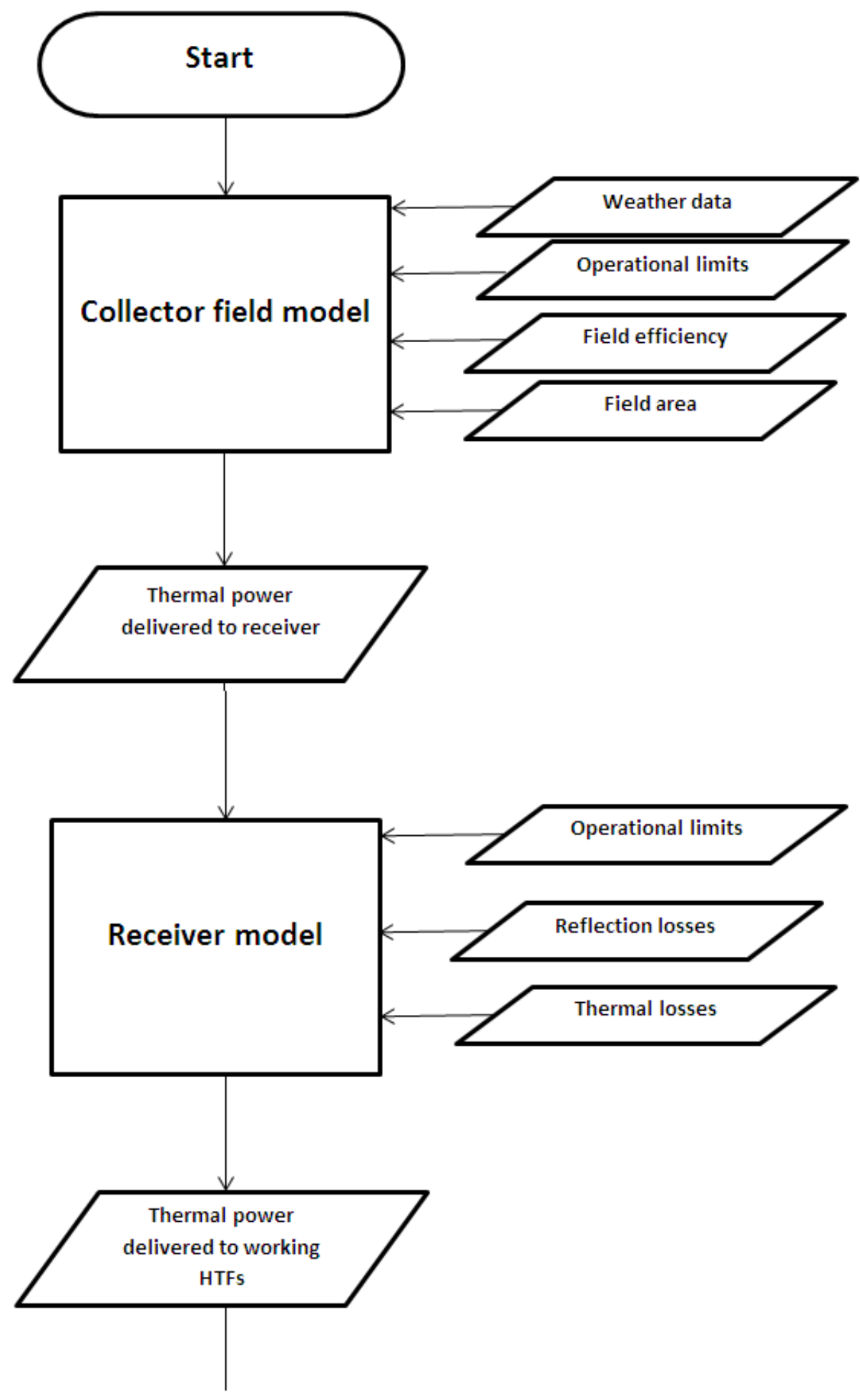




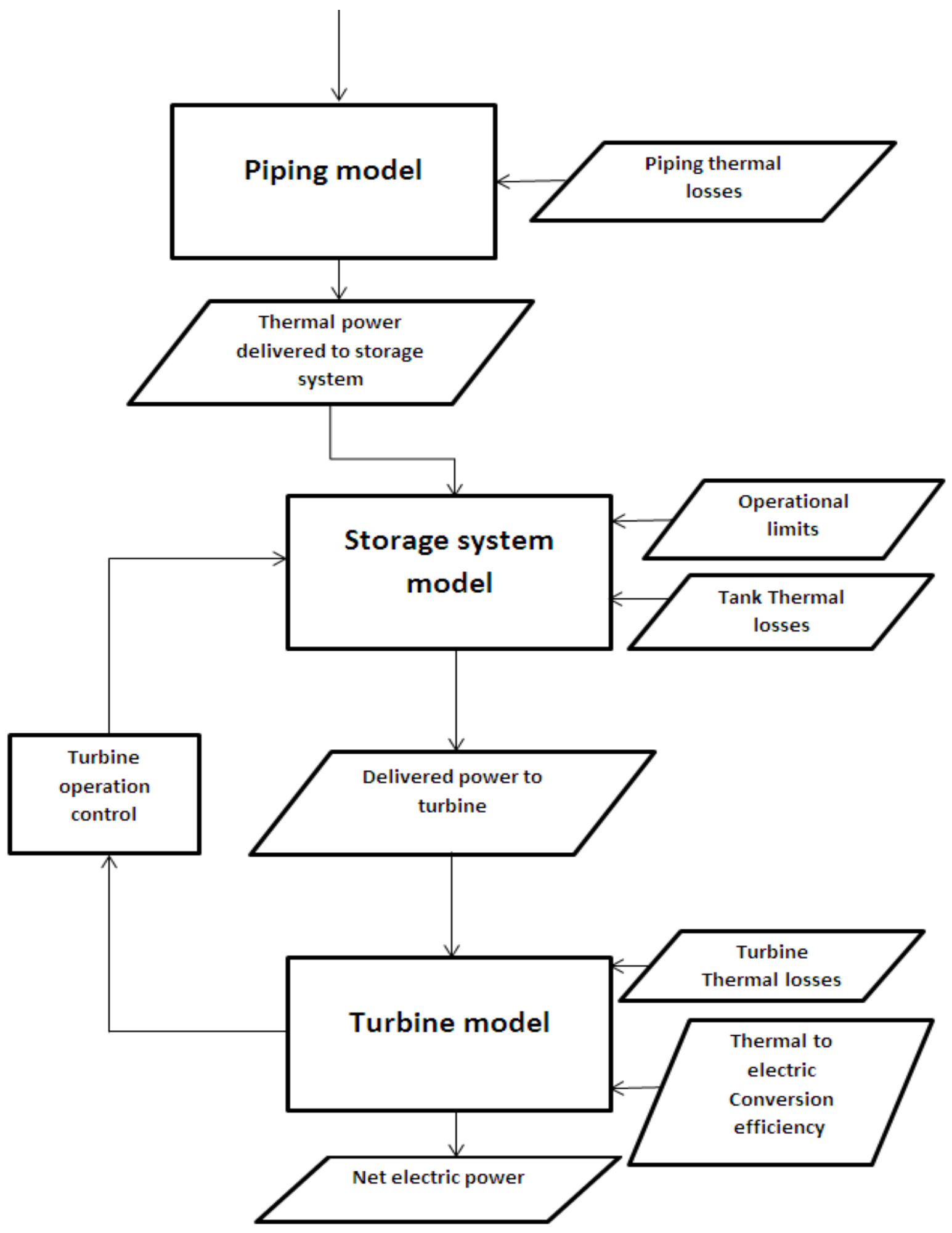

Fig. 7. The calculating program flow diagram. 


\section{EXAMPLE OF DESIGN DETERMINATION FOR A CONCENTRATED SOLAR} THERMAL POWER PLANT

\section{A. USING THE MATLAB CODING}

The following results represent a summarized executed outputs using MATLAB coding. These design determination for a prime power plant $12 \mathrm{MW}_{\mathrm{e}}$ capacity for example. By entering the required inputs then run the MATLAB coding, the determination is executed as following:

1. Daily (24 hour) incident solar radiation overall year in monthly profile, $\mathrm{kW} / \mathrm{m}^{2}$.

dally (24 hour) incident solar radiation per month of the year
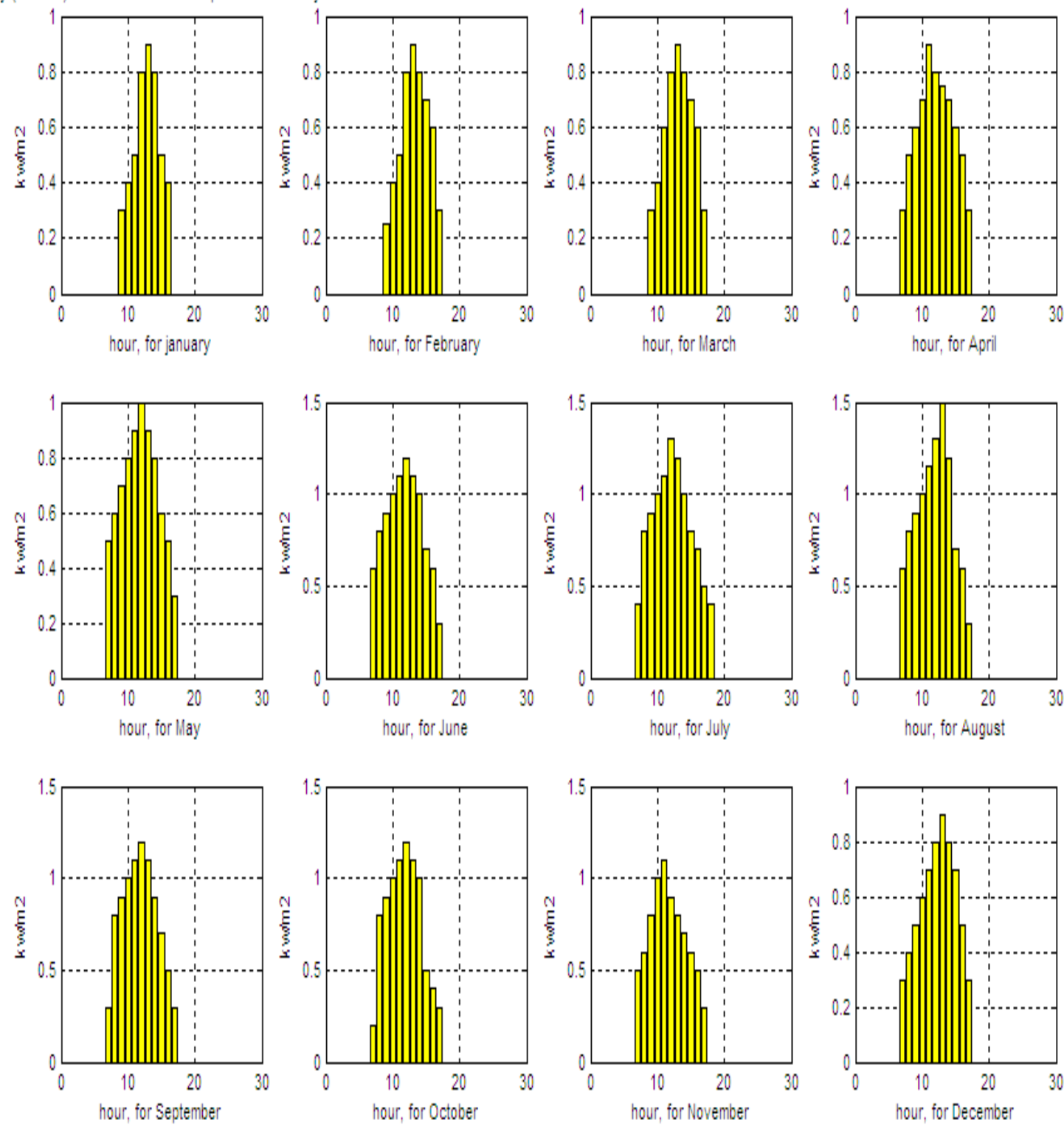

Fig. 8. Plot of daily incident solar radiation overall year in monthly profile. 
2. Daily power incident on receiver overall year in monthly profile, $\mathrm{MW}_{\mathrm{t}}$.
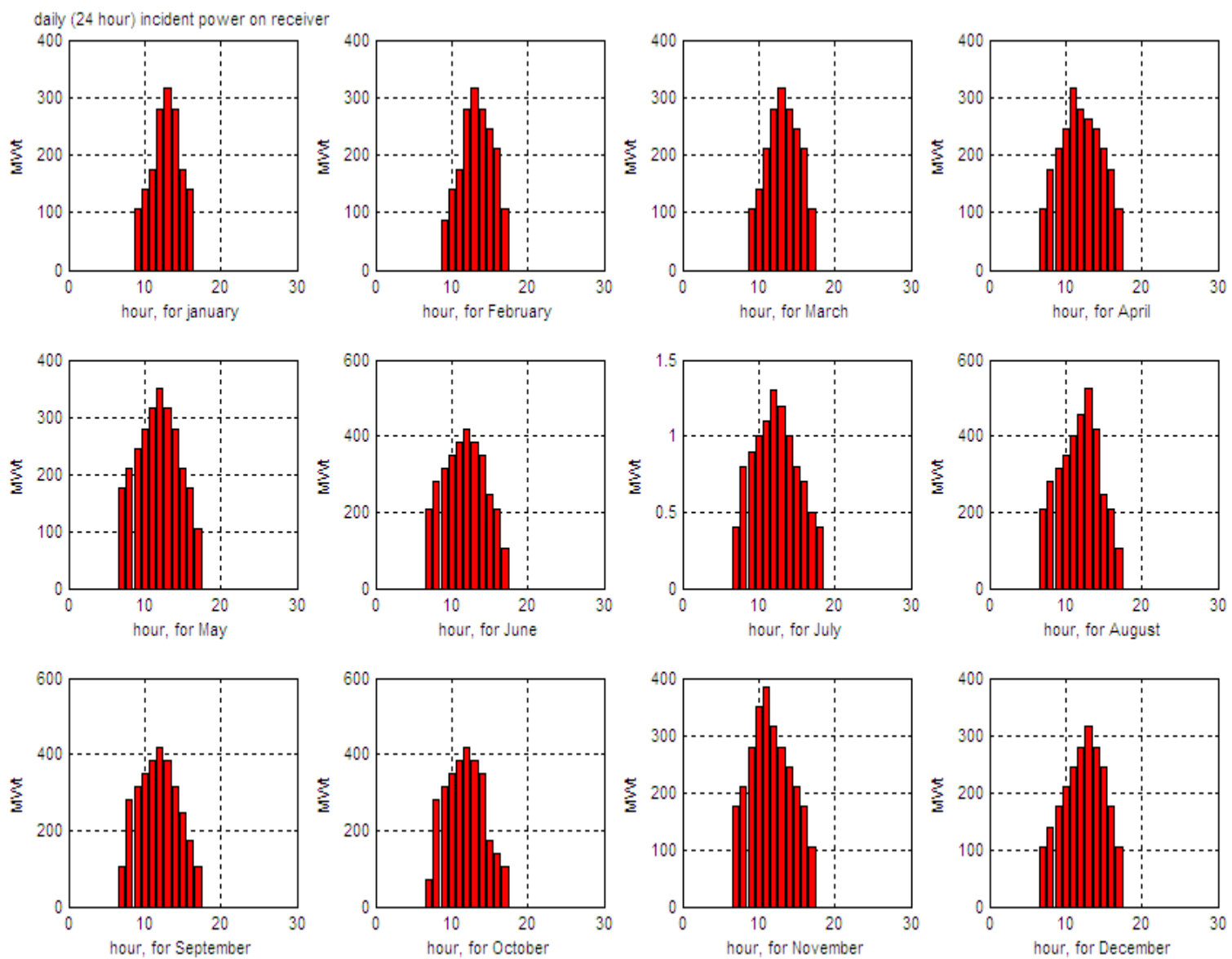

(Fig. 9) Plot of daily power incident on receiver overall year in monthly profile.

3. Daily average incident energy on receiver overall year in monthly profile, $\mathrm{MW}_{\mathrm{t}} \mathrm{hr}$.

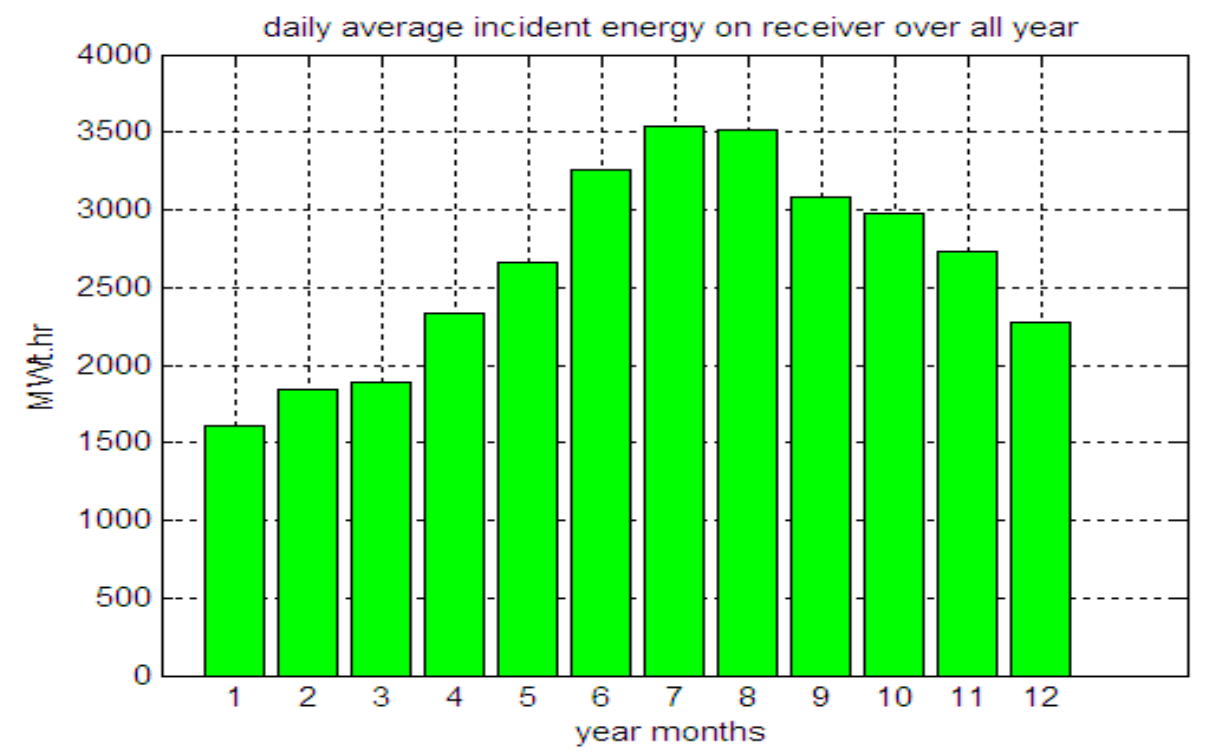

(Figure 10) Plot of daily average incident energy on receiver overall year. 
4. Daily thermal power delivered to the working fluid overall year in monthly profile, $\mathrm{MW}_{\mathrm{t}}$.

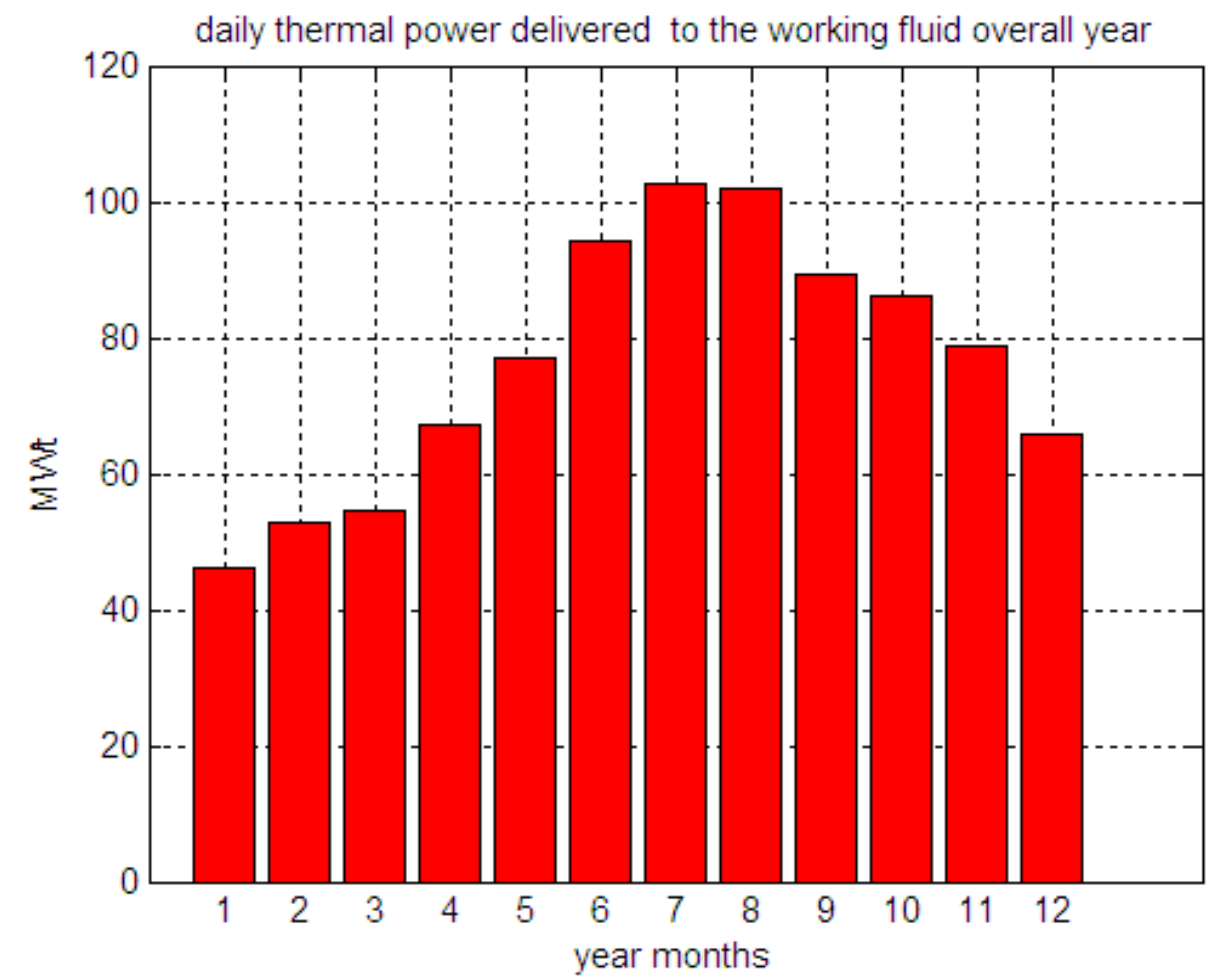

(Figure 11) Plot of daily thermal power delivered to the working fluid overall year.

5. Daily thermal energy delivered to the working fluid overall year in monthly profile, $\mathrm{MW}_{\mathrm{t}} \cdot \mathrm{hr}$.

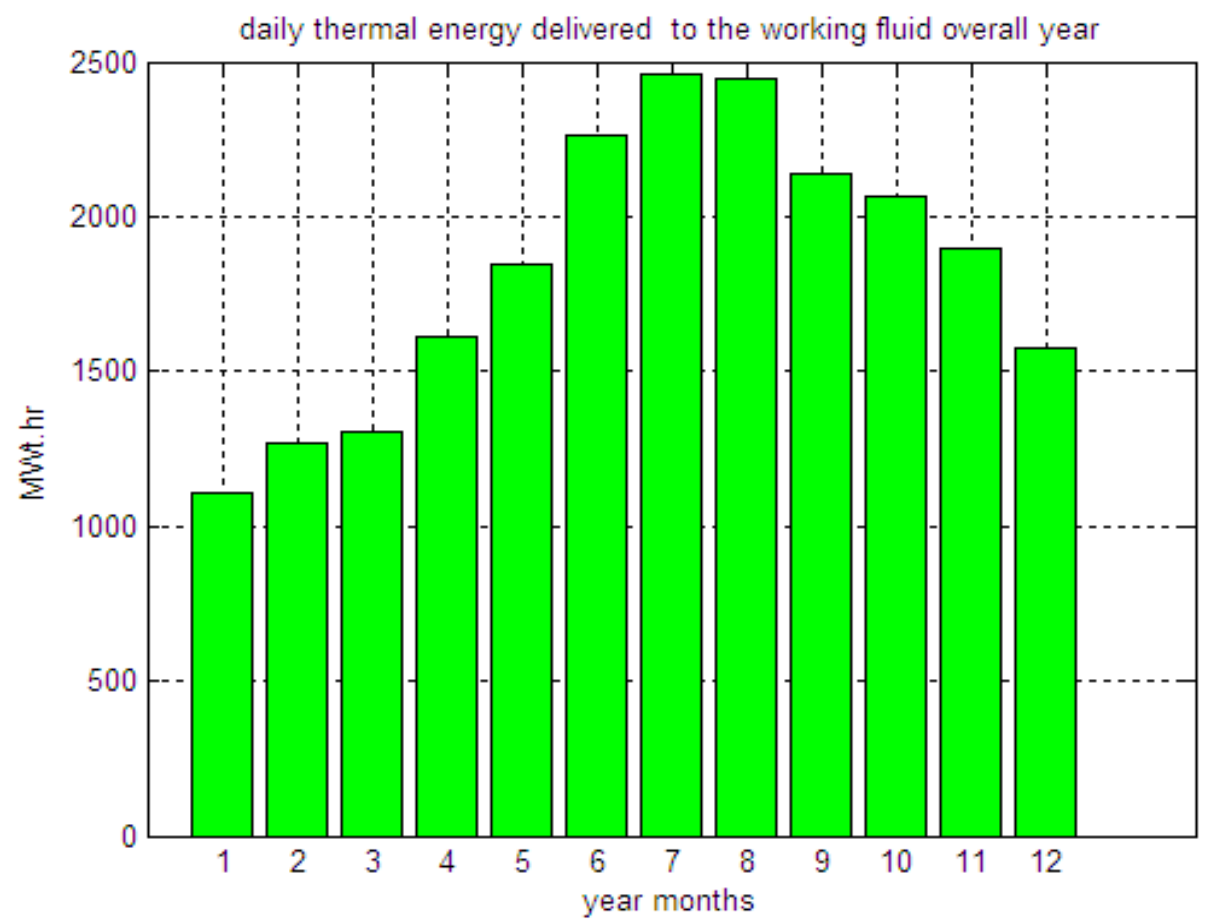

(Figure 12) Plot of daily thermal energy delivered to the working fluid overall year. 
6. Daily net electrical power overall year in monthly profile, $M W_{\mathrm{e}}$.

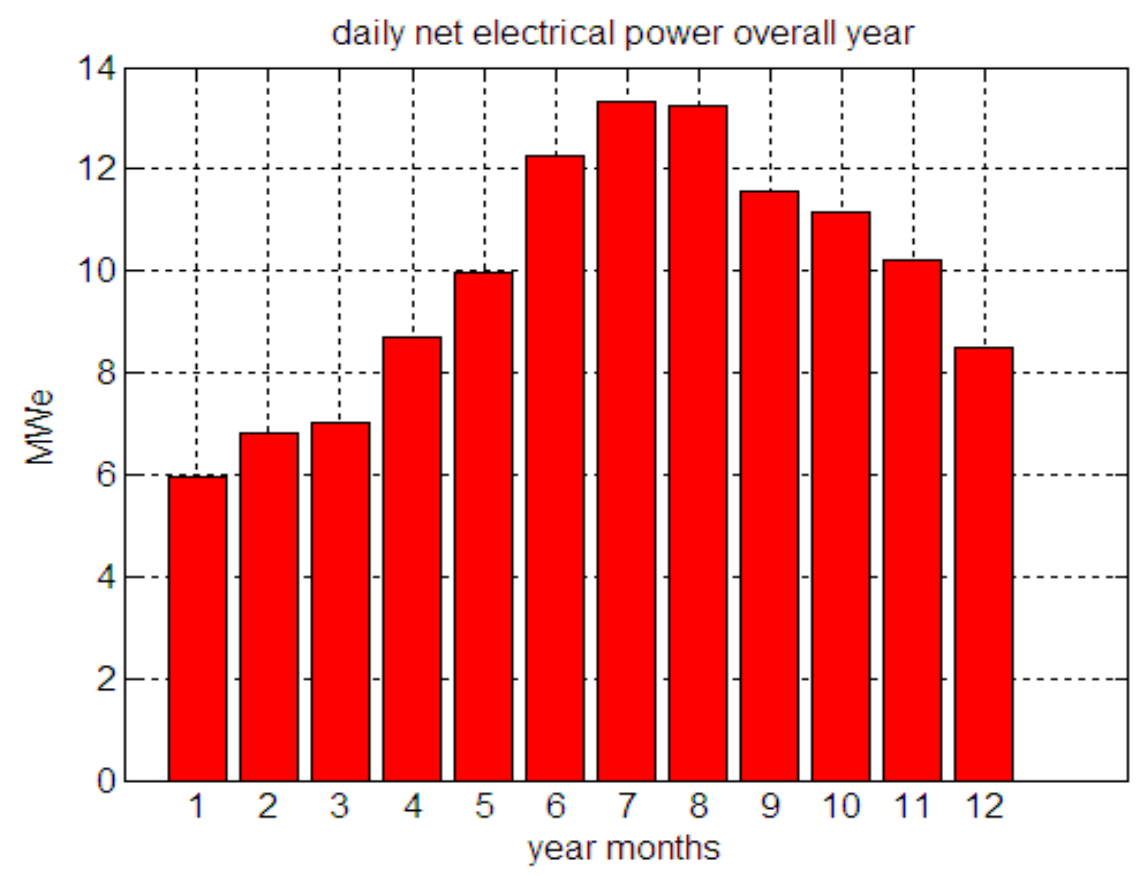

(Figure 13) Plot of daily net electrical power overall year.

7. Daily net electrical energy overall year in monthly profile, $M W_{e} \cdot h r$.

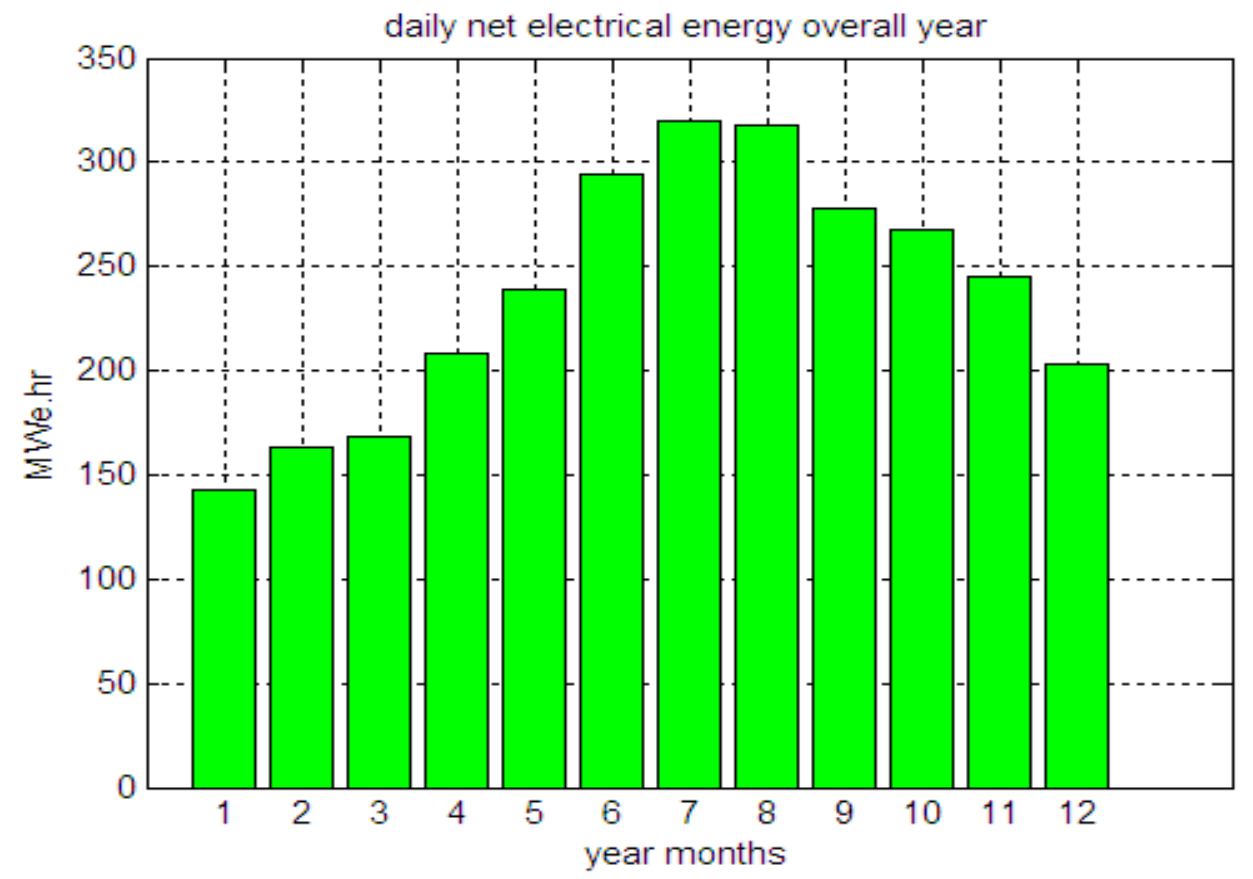

(Figure 14) Plot of daily net electrical energy overall year.

8. Maximum net electric power $=13.3198 \mathrm{MW}_{\mathrm{e}}$.

9. Net annual energy $=86,604 \mathrm{MW}_{\mathrm{e}} \cdot \mathrm{hr}$.

10. Station land area $=1,500,000 \mathrm{~m}^{2}$. 
B. USING THE SAM "SOLAR ADVISOR MODEL" SOFTWARE

The next results represent a summarized executed outputs using SAM software. These design determination for a prime power plant $12 \mathrm{MW}_{\mathrm{e}}$ capacity for example. By entering the required inputs then run the simulation, the determination is executed as following:

1. Monthly output power, $\mathrm{KW}_{\mathrm{e}} \cdot \mathrm{hr}$.

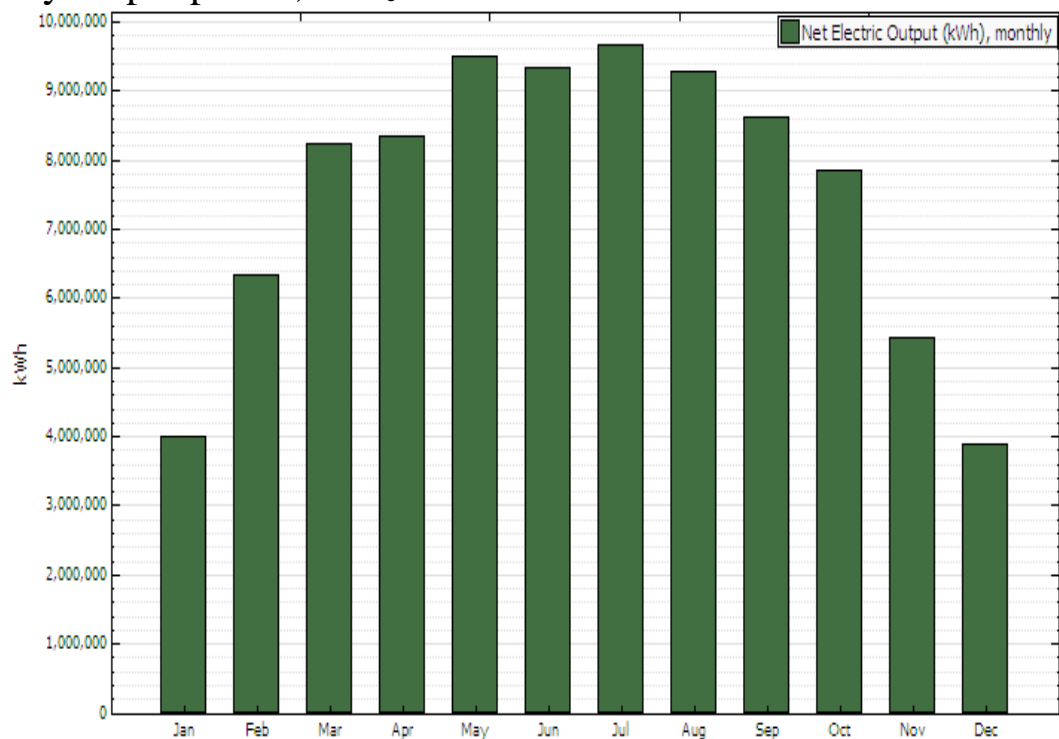

(Figure 15) Plot of "monthly output power".

2. Annual energy flow, $\mathrm{KW}_{\mathrm{e}} \cdot \mathrm{hr}$.

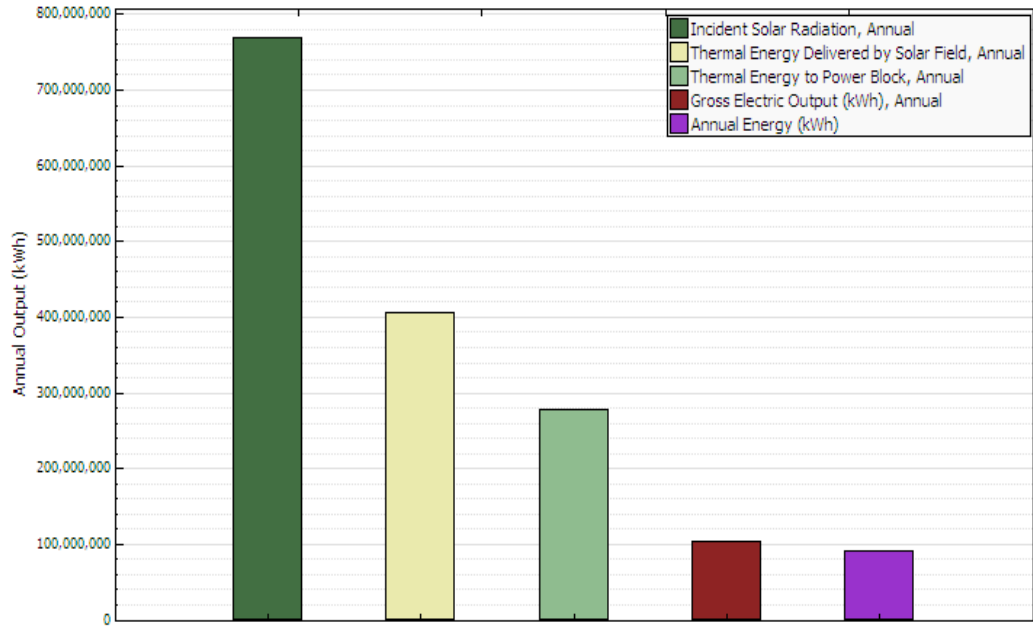

(Figure 16) Plot of "annual energy flow".

3. Maximum net electric power $=12 \mathrm{MW}_{\mathrm{e}}$

4. Net annual energy $=86,885.822 \mathrm{MW}_{\mathrm{e}} \cdot \mathrm{hr}$.

5. Total land area $=430.57$ acres. $=1,742,455 \mathrm{~m}^{2}$

6. Capacity factor $=82.7 \%$.

\section{CONCLUSION}

The main objective of this paper is a construction of a concentrated solar thermal plant model which utilizes a power cycle for electrical power generation, and evaluate general method to modeling then subsequently design determination (using MATLAB coding) in easy output profile without any complexity. These modeling and designing could to apply for all 
concentrated solar power collecting techniques which are using in the solar thermal power plants. Before the modeling, the solar thermal power plant components are configured, because the modeling is based on analysis of components job, how are working?, and operation status. After explanation of these components, it's easy to make the mathematical equations to determine its resulting power. Also, this modeling is new compact and has an advantage that the expressions of most plant portions are free of any complex or thermal details that describe the conventional model

Using the modeling equations in MATLAB coding, the power flow values at any CSTPPs portion is determined. Also the matlab coding can be edited to create other many outputs, or modify any statement. Also SAM software using is easier than the MATLAB coding, but its executed outputs are much summarized. In other words, we use SAM software to verify the accuracy of MATLAB coding results.

The design is determinated and executed for a concentrated solar thermal power plant Using MATLAB coding. For example, to design the prime plant which has capacity $12 \mathrm{MW}_{\mathrm{e}}$, the very important outputs are executed to determine this plant design. Also, SAM software is used to determine of the same prime plant. Although, these executed SAM's outputs are much summarized, the main goal of SAM using is verifying the accuracy of MATLAB coding results. By comparison of the determination results between MATLAB coding and SAM software using, there are approximately the same results as net electrical power, annual energy and used land area. This comparison is verifying the accurate determination which executed from MATLAB coding.

\section{REFERENCES}

[1] Zekai Sen, "Solar Energy Fundamentals and Modeling Techniques. Atmosphere, Environment, Climate Change and Renewable Energy", Istanbul Technical University, Faculty of Aeronautics and Astronautics, Dept. Meteorology, Campus Ayazaga, Istanbul, Turkey, (2008).

[2] Werner Vogel and Henry Kalb, "Large-Scale Solar Thermal Power Technologies, Costs and Development", the Physics Institute at the University of Karlsruhe, Germany, Sandia National Laboratories, National Renewable Energy Laboratory U.S. Department of Energy (2010).

[3] Mukund R. Patel, Ph. D., and P. E. , "Wind and Solar Power Systems", U.S. Merchant Marine Academy, New York, Formerly; Principal Engineer, Westinghouse Reasearch Center (1999).

[4] THORSTEN A. STUETZLE, "Automatic Control of the $30 \mathrm{MW}_{\mathrm{e}}$ SEGS Parabolic Trough Plant", UNIVERSITY OF WISCONSIN-MADISON, (2002).

[5] Ricardo Vasquez Padilla, "Simplified Methodology for Designing Parabolic Trough Solar Power Plants", University of South Florida, (April 4, 2011).

[6] ANGELA M. PATNODE, "Simulation and Performance Evaluation of Parabolic Trough Solar Power Plants", UNIVERSITY OF WISCONSIN-MADISON, (January 10, 2006).

[7] D. YOGI GOSWAMI, FRANK KREITH, and JAN F. KREIDER, "PRINCIPLES OF SOLAR ENGINEERING, $2^{\text {nd }}$ edition", (2001).

[8] Dr. P. Muthukumar, "Thermal Energy Storage: Methods and Materials", Indian Institute of Technology Guwahati, INDIA, (2011).

[9] ANDREW C. MCMAHAN, "Design \& Optimization of Organic Rankine Cycle Solar Thermal Power plants", UNIVERSITY OF WISCONSIN-MADISON, (2006).

[10] Soteris Kalogirou, "Solar energy engineering: processes and systems, $1^{\text {st }}$ edition", Cyprus UNIVERSITY OF Technology, (2009).

[11] Clifford K. , "Software and Codes for Analysis of Concentrating Solar Power Technologies", Sandia National Laboratories, the United States Department of Energy, (December, 2008).

[12] Silvano Vergura, and Virginio Di Fronzo, "Matlab based Model of $40 \mathrm{MW}_{\mathrm{e}}$ Concentrating Solar Power Plant", Department of Electrotechnics, Politecnico di Bari, Italy, (March 30, 2012).

[13] Pegah HASELI, and Farid C. CHRISTO, "Thermal Analysis of a $40 \mathrm{MW}_{\mathrm{e}}$ Dish-Based CSP Plant Using Measured Solar Data", University of South Australia, Adelaide - Australia, (December, 2012).

[14] Ravi Kiran Musunuri, David Sánchez, and Ramon Rodriguez, "SOLAR THERMAL ENERGY", Energy Engineering, university of Gavle, (October, 2007).

[15] Soteris Kalogirou, "Recent Patents in Solar Energy Collectors and Applications", Higher Technical Institute, Cyprus, (November 27, 2006). 
[16] David f. Griffiths, "an Introduction to matlab", Department of Mathematics, The University of Dundee, Stockholm, Sweden, (August, 2001).

[17] R. Guédeza, J. Spellinga, B. Laumerta, and T. Franssona,“Optimization of thermal energy storage integration strategies for peak power production by concentrating solar power plants", Department of Energy Technology, KTH Royal Institute of Technology, Stockholm, Sweden, (2013).

[18] The International Energy Agency (IEA), "Technology Roadmap: Solar Thermal Electricity", 2014 edition, (2014).

[19] Luqmaan Habib, Mohamed I. Hassan, and Youssef Shatilla, "A realistic numerical model of lengthy solar thermal receivers used in parabolic trough CSP plants", Department of Mechanical and Materials Engineering, Masdar Institute of Science and Technology, Abu Dhabi, UAE, (2015).

[20] M. Alguacil, C. Prieto, A. Rodriguez, and J. Lohr, "Direct steam generation in parabolic trough collectors", solar engineering college, Spain, (2013).

[21] Rubén Abbas, José M. Martínez-Val, Javier Muñoz-Antón, Manuel Valdés, Alberto Ramos, Antonio Rovira, Maria J. Montes, Hani Sait, Ricardo Muñoz, Álvaro Gamarra, and Manuel Villén, "A quest to the cheapest method for electricity generation in Concentrating Solar Power plants", Technical University of Madrid, Spain,( 2015 ). 